\title{
Solidarity in All Health Policies
}

\section{Nino Pagliccia MSc}

In the late 1970s, hopes were raised that "Health for All by the Year 2000" was attainable by addressing primary health care. This goal of human well-being seemed achievable and was concisely laid out in the Alma-Ata Declaration, a three-page document that reflected a spirit of social justice, equality and the importance of the role of the state. Most importantly, it recognized health as a human right.

Since that seminal document, the global health community has notably expanded the body of knowledge as well as its formal commitment to good population health. WHO has published documents with inspiring titles such as, Health for All in the 21st Century, Closing the Gap in a Generation: Health Equity through Action on the Social Determinants of Health and Health in All Policies.

It is encouraging to note that these documents and other research reflect an incremental understanding about the notion of health, how to promote it, and the policies needed to maintain it as a social goal. Yet, "health for all" remains elusive, especially for the most vulnerable people in underdeveloped areas. Many of the 2015 Millennium Development Goals' health-related indicators indeed performed below expectations.

Given all this, I would ask: What has been overlooked or not accounted for as we go forward? I suggest that the practice of solidarity in management and delivery of health care may have been largely overlooked as an important tool.

In the European Union (EU) context, the notion of solidarity is well established as delivering assistance to nonprofit sector activities and providing basic social services in order to reduce poverty and inequality between and within EU member states. Its relevance to health is also well recognized: Of 21 targets identified by WHO for the 21st century, "Solidarity in Health" is the very first health target for the European region. In the Americas, PAHO has given solidarity a different connotation, defining it as cooperation among countries and states, which constitutes an essential condition to overcome inequities in health.

Despite the many recommendations about solidarity's importance as a tool for reducing health gaps, I have not seen studies in which solidarity for health has been explicitly adopted or its results evaluated. We need to learn more about solidarity and its impact on health. To this end, Cuba may offer an example of a large-scale experiment on the practice of solidarity vis-à-vis equity in health, one that calls for closer inspection.

My direct observation of Cuba's approach to health care identifies three main domains of action for practicing solidarity: 1) global health; 2) health-promoting services provided to its own citizens; and 3 ) organization of local intersectoral actions to improve health.

The first domain coincides with PAHO's vision of solidarity as cooperation among countries. Cuba has achieved wide recognition for its international medical cooperation, with 51,000 health workers posted in 67 countries in 2015 . The variety of collaborative health initiatives where the greatest motivating factor is solidarity also includes medical education for students from other developing countries.[1]
The second domain is closer to the EU notion of solidarity. Cuba has notably provided state support to its citizens through social service programs with the aim of poverty reduction and social equity. Solidarity and health protection for its citizens are embedded in articles 1 and 50 of Cuba's constitution. This application of solidarity may help explain why, although not a rich country, Cuba has attained such positive health outcomes. Its low infant mortality rate of 4 deaths per 1000 live births in 2015 is just one example.

The third domain refers to local cooperation among different sectors as an organized response to address health problems. Cuba has put in place legislation and structures to support communitybased initiatives and involvement at the municipal level, which in turn facilitate intersectoral actions on social determinants of health (SDH). Their effectiveness requires careful examination.

An exploratory study to determine the extent and strength of intersectoral action on SDH in two Cuban municipalities indicated that the network of sectors involved had fairly strong intersectoral collaboration.[2] This may lend some initial credibility to the relevance of solidarity to health at the local level. It may be somewhat premature and overly ambitious to conclude that Cuba's success in poverty reduction, health care and health equity is the result of the practice of "solidarity for health." Many factors and policies undoubtedly contribute to good health outcomes. However, I would argue that solidarity may offer a hitherto underused lens through which to assess such performance, a new starting point.

Finally, I suggest there is an absence of hard evidence on solidarity as a contributor to good population health and that further research is required. However defined-as a right, a political tool or a societal value; international, national or local in charactersolidarity is already an intuitively helpful notion as implied by WHO and $\mathrm{PAHO}$. And although it may remain as elusive as health equity and good population health, this should not stop our attempts to understand its implications for population well-being. Thus, I believe we need to develop a framework capable of establishing associations among solidarity commitments and practice, health policies, management of well-defined SDH and health impacts.

An exploration of whether solidarity is a necessary condition for effective action on health may prompt a new call for "solidarity in all health policies." $-1 /$ -

1. Morales Ojeda R. Universal Health Coverage: the Cuban Experience. Opening Conference at the International Convention on Public Health Cuba-Salud 2015. Havana, Cuba, April 20-24, 2015. CUBADEBATE [Internet]. 2015 Apr 21 [cited 2016 April 4]. Available from: http://www.cubadebate.cu/opi nion/2015/04/21/ministro-de-salud-roberto-morales-ojeda-expone-experien cia-de-cuba-en-cobertura-universal/\#.VwMZdWMrz9l. Spanish.

2. Pagliccia N, Spiegel J, Alegret M, Bonet M, Martínez A, Yassi A. Network analysis as a tool to assess the intersectoral management of health determinants at the local level: a report from an exploratory study of two Cuban municipalities. Soc Sci Med. 2010 Jul;71(2):394-9.

Submitted: April 4, 2016

Approved for publication: April 5, 2016

Disclosures: None

Correspondence: nino.pagliccia@telus.net 